\title{
Introduction to the Research Handbook on Not-For-Profit Law
}

Matthew Harding

It is an interesting time for not-for-profit law. ${ }^{1}$ Trends in the social, economic and political lives of many communities, and in geopolitics, have created new opportunities - or, viewed from another perspective, new burdens - for the not-for-profit sector, which in turn have demanded new legal and regulatory responses. All over the world, not-for-profits are now expected and funded by government to provide a range of social welfare services and public goods, and increasingly they are expected to compete with for-profit organizations in what many conceptualize as the market for such provision. At the same time, globalization has affected the not-for-profit sector as much as it has any other sphere of human activity, raising particular challenges for states seeking to protect and preserve their political sovereignty and culture as well as their revenue base. The composition and preoccupations of the not-for-profit sector are ever changing, the result of disparate influences such as social media, the appeal of business models and managerial cultures traditionally associated with the for-profit sector, changes in the way politics is conducted, and shifts in conventional morality. Moreover, the profound challenges of rising inequality around the world must be met by the not-for-profit sector as much as by government and the commercial world. The instruments of law and regulation play a fundamental role in ensuring that the not-for-profit sector can thrive in the face of such trends and developments.

Against that rich backdrop, this volume has two purposes. The first is to provide a snapshot of scholarly thinking on a range of questions germane to not-for-profit law in the present day. For the reader seeking to gain an overview of the current state of academic scholarship in relation to the not-for-profit sector, this snapshot will hopefully be of utility. The second purpose of the volume is more ambitious, and arguably more significant: it is to point the way to a research agenda for future academic scholarship on not-for-profit law. By setting such an agenda, this book should reveal aspects of not-for-profit law that are now insufficiently understood, and suggest new ways of thinking about old problems and concerns that stand to enrich and deepen understanding of the not-for-profit sector itself. To the extent that sound scholarship can and does

1 Works on not-for-profit law often begin with a note about terminology, and this book is no exception. The not-for-profit sector goes by many names, including the 'nonprofit sector', the 'third sector', the 'voluntary sector' and the 'charity sector'. Other terms such as 'civil society' are sometimes also used. Part of the burden of this collection is to assist in elucidating the conceptual, functional and normative distinctions between the different ideas reflected in these various labels. For that reason, and because it would be the work of a second book to do so, I make no effort here to explain the taxonomical distinctions (if any) reflected in the different names by which the sector is called. 


\section{Research handbook on not-for-profit law}

inform and improve public policy and law reform, the hope is that the chapters in this book will contribute, even in a modest way, to the project of making not-for-profit law around the world the best it can be.

At the same time, there is another ambition underpinning this collection: the hope is that it will play a role in constituting the study of not-for-profit law as a distinctive and important sub-discipline of the study of law, generally speaking. When lawyers think taxonomically - and they do so all the time - they do not often imagine 'not-for-profit law' to be a distinctive category, in the way that 'family law' or 'company law' might be. Leaving aside philosophical questions about what constitutes a sound legal taxonomy, it seems plausible to suggest that some benefit might be derived from lawyers understanding 'not-for-profit law' to be a distinctive category of law with its own special preoccupations and concerns. For example, such an understanding might, over time, assist in generating a community of practice that takes a special interest in not-for-profit law and, more generally, in creating the legal conditions under which the not-for-profit sector can flourish. That sort of community of practice is well placed to steward improvements to the legal and policy settings within which not-for-profits operate, and to nurture professional advisers who are adequately trained to assist the not-for-profit sector in carrying out its various purposes. These aims depend in important ways on the work of academics, who have been the traditional custodians of legal taxonomy. If, in our research and teaching, we can help to constitute 'not-forprofit law' as a field of study, we can expect to influence how the legal profession conceives of not-for-profit law more broadly, and indeed public perceptions of that body of law as well.

The contributors to this collection are drawn from a range of jurisdictions and disciplinary traditions. Many of them are established leaders in the field; others are emerging as the leaders of tomorrow. Together, they lend the book a breadth of perspective that one author could never hope to achieve. This is not to say that all relevant topics have been covered. For example, the book includes little discussion of the current state of not-for-profit law in some of the world's most powerful nations, such as China and India; ${ }^{2}$ nor does it address the important questions about associational life and the not-for-profit sphere that so preoccupied sociologists such as Robert Putnam in the 1980s and 1990s. ${ }^{3}$ These gaps, and no doubt many others, can only be counted shortcomings of the book, and readers are urged to recall that no one book can do everything. If a sense of what is missing from the chapters collected here motivates further scholarship to fill gaps, then that itself may be counted a success of this book. In any event, the various contributors have undoubtedly produced a rich array of work, the product of a remarkable range and depth of scholarship, insight and experience that I, for one, find inspiring and humbling.

2 The exception is the chapter by Myles McGregor-Lowndes, which discusses China.

3 See, eg, Robert D Putnam, Bowling Alone: The Collapse and Revival of American Community (Simon and Schuster 2000). 


\section{THEORIES OF THE NOT-FOR-PROFIT SECTOR}

Questions about not-for-profit law lead ineluctably to deeper questions about that to which not-for-profit law addresses itself. What does it mean to talk about a 'not-forprofit sector'? How is such a sector to be distinguished analytically or functionally from other sectors of the economy: the household sector, the for-profit sector, and the government sector? Why is there a not-for-profit sector (however defined)? What does such a sector do that cannot be done (at all, or as well) by other sectors? What is the particular value of not-for-profit activity in light of fundamental normative commitments? The first part of the collection traverses fundamental questions such as these, from a variety of theoretical perspectives.

No book purporting to cover the field of scholarship on not-for-profit law would be complete if it did not include the perspective of economic analysis in its mix; after all, economists have done more than any other scholars to advance knowledge and understanding of the not-for-profit sector. ${ }^{4}$ Thus it is fitting that Richard Steinberg and Brian Galle should commence this collection with a law and economics perspective. In a truly bravura performance, Steinberg and Galle range over an array of questions and topics that have engaged and ought to engage economists in relation to the not-forprofit sector since the pioneering work of Burton Weisbrod and Henry Hansmann was first published several decades ago. ${ }^{5}$ Their chapter contains a wealth of insights on the non-distribution constraint (usually viewed by economists as the sine qua non of the not-for-profit sector), the so-called 'three failures' view of the role of the sector in a modern mixed economy, numerous regulatory questions about not-for-profits and those who support them, and other matters such as the optimal scale and diversity of not-for-profit organizations. Steinberg and Galle provide a superb snapshot of the state of economic scholarship on the sector today, and they point the way to future research in that tradition.

The perspective of law and economics grounds what Rob Atkinson calls the 'standard model' of the role of the not-for-profit sector. According to the standard model, the not-for-profit sector is the preferred source of goods and services in circumstances where the family, the government and the for-profit sectors fail to deliver the goods and services in question. In addition, as Atkinson points out, the standard model begins its analysis of the not-for-profit sector by assuming that people have preferences for goods and services, preferences that have equal weight and value, and then asking questions about the most efficient satisfaction of those preferences. In his chapter, Atkinson argues - in characteristically sparkling prose - that we would do well to begin thinking about the not-for-profit sector from a radically different perspective than that which underpins the standard model. Atkinson finds this perspective in

4 A helpful conspectus and critique of that contribution is contained in Richard Steinberg, 'Economic Theories of Nonprofit Organizations' in Walter W Powell and Richard Steinberg (eds), The Nonprofit Sector: A Research Handbook (2nd ed, Yale University Press 2006) 117.

5 See, eg, Burton Weisbrod, 'Toward a Theory of the Voluntary Nonprofit Sector in a Three-Sector Economy' in Edmund S Phelps (ed), Altruism, Morality and Economic Theory (Russell Sage Foundation 1975) 171; Henry B Hansmann, 'The Role of Nonprofit Enterprise' (1980) 89 Yale Law Journal 835. 


\section{Research handbook on not-for-profit law}

neo-classical republican theory. From a republican point of view, the not-for-profit sector is not the last resort when other sectors fail: it is the source of important insights about all four sectors of the economy and their point and purpose. Moreover, the republican viewpoint notices the ways in which the not-for-profit sector seeks to shape and inform preferences, as opposed to simply satisfying them once formed. Using the example of education as a type of good provided by all four sectors of the mixed economy, and drawing on ancient and modern thought, Atkinson constructs a powerful argument for a flourishing not-for-profit sector oriented towards a vision of the common good grounded in scholarly reflection on questions of value.

Adam Parachin takes up questions about the justification of the state's treatment of charities from the liberal perspective that has too often neglected such questions. He does me the signal honour of exploring liberal perspectives on charity law by undertaking a searching and insightful critique of my book, Charity Law and the Liberal State. ${ }^{6}$ Parachin rightly points out that my book does not do enough to address and understand the particular ways in which the liberal state, with an eye to the value of autonomy, promotes the pursuit of charitable purposes. He also questions whether I defend sufficiently my chosen methodology of seeking to interpret charity law 'from within', and he worries that my treatment of political purposes reveals that my primary concern is not charity law per se but rather the duties and responsibilities of the liberal state. However, Parachin's most penetrating objection lies in his argument that my account of charity law fails to explain why the state, via charity law, promotes only autonomy-enhancing purposes that are pursued altruistically. Parachin's chapter both demands that I spell out in various ways the commitments and arguments of my own work, and maps out a future research agenda for liberal thinkers with an interest in charity law. ${ }^{7}$

Fr Brian Lucas presents a vision of the value and role of the not-for-profit sector that is grounded in one of the most venerable and influential comprehensive worldviews in human history: the teachings of the Roman Catholic Church. Drawing on Catholic social teaching, as articulated in Scripture and various authoritative pronouncements of the church, Lucas describes the ways in which a flourishing not-for-profit sector, supported but not suffocated by the state, is an expression of the dignity and worth of individual people, the commitment to the common good that is central to Catholic ethics and morality, the solidarity that lies at the heart of a well-ordered society, the principle of subsidiarity according to which local action and solutions are to be preferred, and the priority of the needs of the poor over the wants of the rich. In a world in which individuals are increasingly alienated from each other (social media notwithstanding), and in which inequality grows and consolidates at a frightening pace, Catholic social teaching offers us a powerful set of tools for critique and political action, and it reminds us that the not-for-profit sector is central to the solutions that it prescribes.

6 Matthew Harding, Charity Law and the Liberal State (CUP 2014).

7 For important recent contributions to that research agenda: Nick Martin, 'Liberal Neutrality and Charitable Purposes' (2012) 60 Political Studies 936; Adam Parachin, 'Charity, Politics and Neutrality' (2016) 18 Charity Law and Practice Review 23. 


\section{THE COMPOSITION AND SCOPE OF THE NOT-FOR-PROFIT SECTOR}

If Part I of the collection focuses on the conceptual and normative unity of the 'not-for-profit sector', Part II turns to a more granular assessment of the composition of the sector in different jurisdictions, as well as the difficult cases that arise at or near the boundaries between the categories of 'not-for-profit', 'for-profit', and 'government'. Part II also touches on the forms by which the not-for-profit sector organizes itself. Among the matters discussed in Part II are some of the most contested questions in not-for-profit law today, such as the question whether charities may carry out tax exempt profit-making activities unrelated to their animating purposes.

The first chapter in this part is by one of the giants of the field: Myles McGregorLowndes. McGregor-Lowndes provides an overview of the idea of the not-for-profit sector, including the central organizing idea of the 'non-distribution constraint'. Along the way, he reminds us that not-for-profit activity predates the idea of the not-for-profit sector by thousands of years and he traces the intellectual origins of modern thinking about the sector in the work of Henry Hansmann and others. McGregor-Lowndes then introduces us to the not-for-profit sector today in four jurisdictions: the United States, the United Kingdom, Japan and China. In the former two jurisdictions, with their neo-liberal politics, the non-distribution constraint has come under increasing pressure, generating challenges in continuing to demarcate a not-for-profit sector. In the latter two jurisdictions, the identity of the sector has been challenged in different ways, due to heavy state involvement in the delivery of goods and services with which the sector is traditionally associated. McGregor-Lowndes shows us that the idea of a not-for-profit sector abides notwithstanding the various challenges faced by the sector around the world, and, at the same time, that a true understanding of the sector demands a firm grasp of social, economic and political settings.

Darryn Jensen's chapter reflects on where the distinction might lie between the not-for-profit sector and government. Drawing on legal and social history reaching back to medieval England, Jensen makes the important point that the not-for-profit sector cannot be distinguished from government based on the nature of the purposes that are pursued within it. Rather, the distinction must lie in the voluntary means by which not-for-profits organize and operate and the coercive means by which government does so. Jensen then turns to the intellectual history of the idea of civil society, and develops an argument that government, as a form of association, ought to choose the scope of its operations with sensitivity to the ways in which voluntary associations may do a better job. Finally, Jensen considers the complexities that unsettle the distinction between the not-for-profit sector and government where not-for-profit organizations are controlled financially and in other ways by government.

The boundary between the commercial and not-for-profit sectors is one of the hottest topics in not-for-profit law today, and in his chapter, Ben Leff undertakes a searching review of that boundary. Leff argues persuasively that we ought to evaluate the legal treatment of the boundary with not only the tax concessions afforded to not-for-profits in view, but also the value associated with the not-for-profit brand. Thus, Leff observes that when thinking about new legal forms enabling social enterprise, we should assess the risk that such forms might generate confusion in relation to the boundary between 
commercial and not-for-profit spheres. Confusion seems especially likely in circumstances where social enterprise forms are largely beyond the regulatory scrutiny of the state, and in this connection, Leff's discussion of the Benefit Corporations and Social Purpose Corporations that form part of the legal landscape in the United States is both illuminating and concerning. Leff's chapter is an important reminder of the significance of the expressive or signalling functions of not-for-profit law and regulation, functions that play an important role in sustaining an effective and efficient not-for-profit sector.

Historically, the charitable trust has played a prominent role as a means for carrying out not-for-profit activity. In his chapter, John Picton explores a key question that attends this central not-for-profit form: is the guiding principle for the legal effectuation of charitable trusts respect for the intention of charitable donors, or is it to be found in considerations of public policy? Picton argues forcefully that in at least one respect it is the latter, even though it is often assumed by courts and commentators alike to be the former. Using dialectical methods, Picton presents a masterly overview of the historical development of the cy-pres doctrine by which charitable trusts are reformed. He shows that, while an interest in donor intention is never absent from the cy-pres scene, it is usually subordinated to public policy considerations, whether these be grounded in harm minimization or simply efficient deployment of charitable assets. As with other chapters in this part of the book, Picton's analysis raises some profound questions about where control and oversight of the not-for-profit sector ultimately lies: is it with citizens acting individually or in the associational sphere, or is it with the state?

\section{NOT-FOR-PROFIT ORGANIZATIONS AND THE CONSTITUTION}

One dimension of not-for-profit law that has historically received less attention than it deserves is its constitutional aspect. How is not-for-profit law affected by the constitutional order in which it exists in any given jurisdiction? Part III of this collection explores this question with reference to several different themes; one of the lessons that emerges from the chapters in this part is that traditional ways of organizing how we think about a constitutional order are confounded by not-for-profit law. The study of not-for-profit law should therefore be of interest to constitutional and legal theorists generally.

One key question that arises for not-for-profit organizations is whether, in a constitutional order, they fall to be governed by public law or private law. Kathryn Chan has thought as much about this topic as anyone. ${ }^{8}$ In her chapter, Chan argues that it is plausible to associate public law with collective projects and goals, and private law with individual projects and goals. With this distinction in view, Chan turns to charity law, arguing that it is best understood as a public-private hybrid in which individual autonomy is valued in certain respects, and collective priorities in others. Chan then contrasts charity law with statutory schemes establishing social enterprise vehicles in the United Kingdom and British Columbia. She concludes that the law enabling and

\footnotetext{
8 See Kathryn Chan, The Public-Private Nature of Charity Law (Hart Publishing 2016).
} 
regulating the UK's 'community interest company' balances individual and collective goals in much the same way as charity law; in contrast, Chan associates the legislation governing British Columbia's 'community contribution company' with a distinct shift towards valuing individual autonomy over collective priorities. Throughout, Chan argues that the public/private distinction remains both relevant and useful when considering charity law in particular and the legal order generally.

François du Toit tackles one of the more interesting topics in not-for-profit law today: to what extent, and in what ways, should not-for-profit activity be constrained by the norms of anti-discrimination law? Drawing on the recent experience of his home country of South Africa, as well as jurisprudence and academic literature from around the world, du Toit presents a masterly overview of the various questions and challenges raised by this difficult topic, which demands careful consideration of the distinction between public and private, the values of equality and autonomy, and the proper remit of private law in a constitutional order. Du Toit shows that questions about not-forprofits and discrimination arise in common law, civilian and hybrid jurisdictions alike; he also shows that those questions cannot be confined comfortably to not-for-profit law. For example, du Toit considers the possibility that if charitable trusts entailing discrimination are to be struck down or varied on anti-discrimination grounds, then so must discriminatory 'private' trusts be struck down. His chapter therefore reminds us that the boundaries between not-for-profit law and other bodies of law are not always clear-cut.

The legal treatment of charities that engage in political advocacy and election campaigning has long been controversial, but that controversy has been especially pronounced in recent years in Australia. In 2010, the High Court of Australia departed from the longstanding rule, first propounded in Bowman v Secular Society Ltd, that an organization whose purpose is too 'political' cannot be a charity in law; 9 that decision has since sparked considerable government interest in and public debate about charities and politics. In her chapter, Jennifer Beard explores some key themes in this debate. She begins by considering how charity advocacy might serve the important constitutional value of political sovereignty; she concludes that it does so, but she questions whether charities should be subsidized to carry out such advocacy except where it serves charitable purposes. Beard then moves to the topic of charities participating in election campaigning. She suggests that the rule in Australia's Charities Act that identifies election campaigning as a disqualifying purpose may fall foul of the implied freedom of political communication in the Australian Constitution. Beard's concerns about the interaction of this implied freedom and charities in politics may prove prescient, as at the time of writing the federal government in Australia is proposing to impose severe restrictions on the capacity of Australian charities to engage in political speech, restrictions that may in due course be tested on constitutional grounds in the High Court.

Pauline Ridge looks at the ways in which freedom of religion might impose demands on not-for-profit law in the United Kingdom. In a wide-ranging chapter, Ridge considers this question with reference to European jurisprudence, but also the charity

9 Aid/Watch Incorporated v Federal Commissioner of Taxation (2010) 241 CLR 539, departing from Bowman v Secular Society Ltd [1917] AC 406. 
law and other common law of the UK itself. Of course, as Brexit looms, the UK's own jurisprudence on this as on a myriad of other matters is likely to become much more important in the years ahead. Ridge argues that the legal definition of 'religion' in not-for-profit law should be as broad as possible, to ensure that freedom of religion is properly respected and that the question of what counts as a religion is kept separate from the question whether a religion should be constrained or interfered with by the state. Ridge further argues that European jurisprudence should be developed with an eye to ascertaining when states might legitimately discriminate between religions, within the 'margin of appreciation' that they enjoy under European law. Finally, Ridge suggests that freedom of religion demands the restoration of a 'presumption' of public benefit in English charity law or the abolition of the public benefit requirement altogether, a suggestion that will resonate with many English readers.

\section{THE LEGAL CONCEPTION OF CHARITY}

The legal conception of charity in the common law tradition is found in what must surely be one of the most intricate and fascinating bodies of law anywhere. In Part IV, some of the world's leading experts on charity law explore aspects of that legal conception. Their contributions underscore a point that cannot be made often enough: even though the legal conception of charity is venerable, it is far from jejune, as the considerable legislative interest around the common law world in defining charity attests. At the same time, the conception of charity in civil law has received little attention, at least from English-speaking writers, and this part of the book aims to fill that gap in a way that is hopefully thought-provoking for both common law and civil law thinkers alike.

Part IV commences with Gino Dal Pont's overview of the history and future of the law of charity. Dal Pont advances a striking thesis: notwithstanding the great expansion over the years in the numbers of organizations recognized as charitable, ${ }^{10}$ the categories of charitable purpose in contemporary charity law remain largely what they were in 1601 when the preamble to the Statute of Elizabeth was promulgated. Dal Pont focuses in particular on the fourth 'head' of charity as described by Lord Macnaghten in the seminal nineteenth-century case of Commissioners for Special Purposes of Income Tax $v$ Pemsel - 'other purposes beneficial to the community' within the 'spirit and intendment' of the Elizabethan preamble. ${ }^{11}$ It is under this fourth 'head' that expansion in the legal definition of charity is often said to have taken place. However, in a sweeping review of the case law, Dal Pont shows that the categories of purpose recognized as charitable under the fourth 'head' have remained remarkably stable across the centuries, and that this stability persists notwithstanding recent legislative restatements of the legal definition of charity across the common law world. Dal Pont's chapter provokes reflection on why the legal definition of charity might have remained

10 A theme on which Dal Pont has written elsewhere: see Gino Dal Pont, 'Charity Law: "No Magic in Words"?' in Matthew Harding, Ann O'Connell and Miranda Stewart (eds), Not-forProfit Law: Theoretical and Comparative Perspectives (CUP 2014) 87.

11 See Commissioners for Special Purposes of Income Tax v Pemsel [1891] AC 531, 583. 
so stable for so long: as he suggests towards the end of the chapter, the answer may lie in the enduring human values that underpin charity law in all places and at all times.

Michael Lubetsky tackles an important topic in charity law that has been understudied to date: the treatment of the legal definition of charity in civilian legal traditions. Lubetsky begins with Roman law, outlining the origins of the civilian approach to defining charity for legal purposes. He then undertakes a fascinating survey of the reception and treatment of English charity law in the United States of America. He demonstrates that, because the Statute of Elizabeth was repealed by many states following independence, US courts came not to rely on the statute and were instead driven to the recognize the civilian origins of English charity law. Finally, Lubetsky engages in a detailed examination of that most famous of all charity law cases, Pemsel, and he emphasizes the ways in which that case demanded reflection on the relation of the legal definitions of charity in the English common law and the Scottish hybrid systems. Throughout, Lubetsky teaches us that common law and civilian legal traditions share common Roman roots and have interacted for centuries in relation to the legal definition of charity. Given all this, it might seem surprising that the architecture and content of the common law of charity looks rather different from its civilian counterpart, a point with which Lubetsky concludes.

If Gino Dal Pont emphasizes stability in the legal definition of charity, Debra Morris in her chapter emphasizes the aspects of that legal definition that have undergone change and fragmentation. Taking as her focus the 'heads' of charity that constitute the core of charity law in many jurisdictions, Morris traces the development of those 'heads' from Elizabethan times, through the seminal Pemsel case, to the modern legislative restatements that may be found across the common law world. Morris then concentrates on three areas in respect of which different approaches are taken in different common law jurisdictions: the charitable status of religion; the charitable status of advancement of education; and the charitable status of sport. In relation to religion, Morris explores the relatively accommodating approach in jurisdictions such as Australia and Ireland, and the more sceptical approach of England and Wales and Scotland. Her treatment of education touches on some of the most hotly contested aspects of charity law in recent times, such as the question whether independent schools should be recognized as charities even where their fees are unaffordable to the poor. Finally, Morris's discussion of sport raises an interesting puzzle about the relation of charity law to social and cultural norms: why do countries with strong and enduring sporting traditions, such as Australia and New Zealand, nonetheless refuse to recognize the promotion of amateur sport as a type of charitable purpose?

The connection between charitable purposes and public benefit is well established, but precisely how and why public benefit must be demonstrated if purposes are to be recognized as charitable in law remains poorly understood, at least in the common law tradition. Mary Synge has extensively studied the public benefit requirement, especially as it applies in the law of England and Wales, ${ }^{12}$ and she brings her deep expertise to bear in her contribution to the collection. Synge argues that common law jurisdictions

12 Mary Synge, The 'New' Public Benefit Requirement: Making Sense of Charity Law? (Hart Publishing 2015). Another equally insightful volume is Jonathan Garton, Public Benefit in Charity Law (OUP 2013). 
once held a shared view about the role of the public benefit requirement in the work of determining whether a purpose is charitable in law. She then outlines the various ways in which that consensus has been fragmented and lost because of legislative and other reforms in different parts of the world. In particular there has been considerable divergence in relation to the requirement, and practice, of 'presuming' or 'assuming' the public benefit of purposes of one or another type, and this divergence has generated much confusion and controversy. Towards the end of her chapter, Synge introduces a provocative and fascinating thesis: does charity law need a public benefit requirement at all, or could all the work of such a requirement be done more clearly and efficiently by the 'heads' of charity coupled with precise and targeted disqualifying rules? This thesis demands careful consideration in all jurisdictions in which the public benefit requirement has grown more prolix and opaque in recent years.

\section{THE TAX TREATMENT OF NOT-FOR-PROFIT ORGANIZATIONS}

Tax is never far from view when the not-for-profit sector is under discussion. Part V of the collection explores the tax treatment of not-for-profit organizations and those who support them. Some important themes are brought to the surface in this part: the challenges of designing and administering tax rules that minimize unnecessary complexity and compliance costs; the vulnerability of the not-for-profit sector to broader political and legal currents in relation to tax; and the ways in which the tax treatment of not-for-profits and their supporters undermine core political values such as equality.

Ann O'Connell begins Part $\mathrm{V}$ with a sweeping review of the interaction of tax systems at the national and sub-national level and the not-for-profit sector. Her chapter ranges widely, starting with an important discussion of nomenclature in relation to the sector, and moving on to an overview of the complexity and diversity of the sector in relation to organizational form, sources of funding, and mission. She then turns to the arguments for and against the tax concessions that have typically been extended to the sector since ancient times, before surveying the treatment of not-for-profit organizations and activities in relation to various taxes, from income tax, to value added tax, to land and estate taxes. O'Connell concludes with a consideration of difficult issues that have arisen in relation to the tax treatment of not-for-profits; these include: the extent to which charities should be subsidized to participate in the political sphere; whether tax concessions should be extended to charities engaging in commercial activity; and the ways in which the tax treatment of charities might be affected by their cross-border activities. O'Connell shows that across the world similar questions and pressures arise in relation to the taxation of not-for-profits, and that analysis of the tax treatment of not-for-profits should take place in conjunction with thinking about nomenclature, the definition of the sector, and regulation.

There is surprisingly little theoretical literature on the tax treatment of not-for-profits, and such literature as there is has long been dominated by economists. Miranda Perry Fleischer's recent work has done much to change that state of affairs; in a series of important articles, she has explored charitable tax subsidies from the perspective of 
libertarian and liberal political philosophy. ${ }^{13}$ In her chapter, Fleischer furthers this work. She argues that the tax subsidies extended to charities are difficult to justify in light of libertarian ideals, because they entail coercing some taxpayers to subsidize the pursuit of purposes that limited government ought not to pursue. She then turns to the liberal tradition of resource egalitarianism, and once again finds charitable tax subsidies wanting because they are inconsistent with equality of opportunity on most liberal understandings of that ideal. Fleischer reaches the interesting conclusion that the best chance of defending charitable tax subsidies from a liberal point of view is on the back of a highly controversial version of resource egalitarianism that is sensitive to expensive tastes and preferences. Her chapter is a salutary reminder that, even though charitable tax subsidies have existed for as long as taxes have been raised, it should never simply be assumed that they are defensible as a matter of political morality. In a world where the revenue base is eroding in many countries, and where inequality is rising at an alarming pace, Fleischer's arguments are especially pertinent and deserve careful attention.

Roger Colinvaux focuses in his chapter on the deduction, for purposes of assessing taxable income, that is available in the United States for donors to 'charitable' organizations. Colinvaux argues that the availability of this deduction has influenced the development of the charity sector, and the law and regulatory framework affecting that sector, in profound ways. For example, Colinvaux argues that, because 'charity' status in the USA triggers both income tax exemptions and deductions for donors, that status is restricted in ways that seem puzzling if the justifiability of exemptions taken on their own is under scrutiny. Moreover, he argues that the coupling of 'charity' status and deductions in US tax law has led to US charity law becoming highly federalized and to the federal tax authority operating as a de facto regulator of the sector. Colinvaux ends his chapter with a powerful argument against the regressive effects of the charitable deduction under US law; for Colinvaux, the deduction distorts the distribution of political power and prioritizes the interests and preferences of the rich, effects that are due to compound in the wake of recent legislative reforms. The solution to such inequities may lie in tax credits as instruments of public policy, or indeed in targeting deductions so that they are available for donations to poor relief and other redistributive charitable purposes.

The emphasis of Fiona Martin's chapter is on the diverse ways in which different jurisdictions handle key aspects of the tax treatment of charities. In a wide-ranging chapter, Martin looks at the law in Australia, New Zealand, England, the United States and Hong Kong. She demonstrates that across these jurisdictions there are substantial differences of approach to important policy questions, for example, relating to the tax treatment of the unrelated business income of charities. In Australia, this income is tax exempt; in New Zealand, it sometimes is; in the United States and Hong Kong, it is taxable in the ordinary case. Similarly, deductions for charitable donors are handled

13 See, eg, Miranda Perry Fleischer, 'Libertarianism and the Charitable Tax Subsidies' (2015) 56 Boston College Law Review 1345; Miranda Perry Fleischer, 'Equality of Opportunities and the Charitable Tax Subsidies' (2011) 91 Boston University Law Review 601; Miranda Perry Fleischer, 'Theorizing the Charitable Tax Subsidies: The Role of Distributive Justice' (2010) 87 Washington University Law Review 505. 


\section{2}

differently across the world: in the USA, deductions are available for donors to 'charities'; in Australia, the availability of deductions is confined to gifts to a different category of organization, the 'deductible gift recipient'. In New Zealand, deductions are limited to corporate donors, and tax credits are available instead to individual donors. Finally, Martin emphasizes the diversity of regulatory structures and frameworks across the jurisdictions under review. Overall, her chapter is a reminder about the complexity of the charity sector and the multiple questions of public policy that attend the tax treatment of it and those who support it.

No one is better versed in the intricacies of the tax treatment of not-for-profits in the United States than Evelyn Brody. In her chapter, she provides an insightful account of those intricacies, which are a product of federalism, constitutional commitments, legislative complexity and political culture. Brody touches on one of the most disturbing influences on US not-for-profit law and regulation in recent times: the notorious decision of the United States Supreme Court in Citizens United $v$ Federal Election Commission, which has allowed tax-exempt funds to be applied for political campaigning purposes via not-for-profit vehicles that are not subject to disclosure laws. ${ }^{14}$ In particular, she discusses the extraordinary sequence of events following Citizens United that led to the head of the exempt entities division of the Internal Revenue Service being threatened with contempt of Congress. Brody also addresses some of the ways in which the IRS functions as a de facto regulator of the not-for-profit sector in the US notwithstanding its mandate to collect and preserve the revenue. She concludes by emphasizing that in the US the goals of not-for-profit law and regulation risk becoming 'collateral damage' in broader tax reforms. Her chapter reinforces the lesson that good not-for-profit law and policy is an achievement that should never be taken for granted, and one that depends on a range of factors beyond the control of the sector and its advocates.

\section{THE REGULATION OF NOT-FOR-PROFIT ORGANIZATIONS}

Regulation of the not-for-profit sector has been around for hundreds of years; indeed, the Statute of Charitable Uses of 1601, the preamble to which is considered by many the fons et origo of the legal meaning of charity the world over, was inspired by regulatory goals. Scholarly interest in not-for-profit regulation has been a more recent phenomenon, but it is growing exponentially. The final part of the book explores some of the key concerns and questions of this expanding body of literature. These range from the foundational principles underpinning not-for-profit regulation to the institutional settings on which successful not-for-profit regulation depends. The final chapter in the collection explores some of these questions from the perspective of the regulator itself, a perspective from which academic scholarship stands to learn much.

Jonathan Garton goes back to basics in his chapter, asking whether there is anything special about not-for-profit regulation as opposed to regulation generally, regulation of the third sector (of which the not-for-profit sector is a part), or regulation of the charity

14 Citizens United v Federal Election Commission 558 US 310 (2010). 
sector (which is a sub-set of the not-for-profit sector). ${ }^{15} \mathrm{He}$ argues that if not-for-profit regulation is to be distinguished from regulation generally, it must be because of its special interest in policing compliance with the non-distribution constraint, not because of any interest it has in minimizing harmful externalities. Garton goes on to engage in an important discussion of the ways in which the regulation of co-operatives properly differs from the regulation of not-for-profits: such difference is justified because of the distinctive market failures associated with the co-operative form. Finally, Garton argues that charities should not be singled out for special regulatory treatment because, from the economic perspective that should underpin sound regulation, they are not substantively different from other not-for-profits; the fact that they are legally distinct is unimportant. Nonetheless, Garton does allude to certain regulatory challenges that are exacerbated in the case of charities because of the requirement that charity assets be applied, sometimes in perpetuity, in the service of particular purposes. With taxonomical and analytical rigour, Garton reminds us that principles of sound regulation of the not-for-profit sector must always be informed by a strong understanding of the specific mischief to be regulated against and the propensity of different forms and structures to generate that mischief.

In addition to his co-authored chapter with Richard Steinberg, the opening chapter of the collection, Brian Galle contributes a sole-authored chapter on the topic of regulation. Galle raises and then addresses several under-explored questions relating to the regulation of not-for-profits. What might justify state regulation of the sector? Under what circumstances might self-regulation be preferable to state regulation? What role does enforcement play in a sound framework of not-for-profit regulation, and who ought optimally to be given the standing on which such enforcement depends? If the value of the not-for-profit sector lies in the diverse range of perspectives that it nurtures and facilitates, then to what extent does government regulation of the sector interfere with that value? To what extent do not-for-profit organizations comply with regulatory and other requirements and why? In working through these questions, Galle suggests that the ideal regulatory framework for not-for-profits is likely to be one in which the state and the sector each play a key role, and to which law, policy and culture make seminal contributions. In many ways, that is already a recognizable framework in many jurisdictions, suggesting that the fundamentals of not-for-profit regulation are often sound even if the details could be improved.

One of the most significant academic voices in recent years on the topic of not-for-profit regulation has been Oonagh Breen. Building on her seminal work with Alison Dunn and Mark Sidel, ${ }^{16}$ Breen's chapter surveys not-for-profit regulation over the past ten or so years in a number of jurisdictions. She presents revealing data comparing different regulators in relation to annual budget, staff numbers, numbers of charities dealt with, and so forth. She also describes the different pressures and priorities of regulators around the world, from the challenges of working in a federal

15 Garton's chapter builds on his previous work on this topic: Jonathan Garton, The Regulation of Organised Civil Society (Hart Publishing 2009).

16 Oonagh B Breen, Alison Dunn and Mark Sidel (eds), Regulatory Waves: Comparative Perspectives on State Regulation and Self-Regulation Policies in the Nonprofit Sector (CUP 2016). 


\section{Research handbook on not-for-profit law}

system faced by the Australian Charities and Not-for-Profits Commission to the searing political scrutiny under which the Charity Commission for England and Wales has operated in recent years. Breen emphasizes points of difference between not-for-profit regulators, but she concludes by emphasizing the common goals to which all such regulators ought to aspire: an accurate and accessible register; data collection and presentation that is appropriate given the diversity of the sector and the public interest in information relating to it; and policies, processes and practices in relation to compliance that are efficient, effective and aligned with public policy goals. Not-forprofit regulators operate under tight budget constraints and, in some jurisdictions, government scepticism about their value; Breen's chapter is based on an account of good not-for-profit regulation that can both guide regulators in challenging conditions and inform arguments for retaining and even augmenting not-for-profit regulation even though it might be perceived as expensive and unpopular.

Susan Pascoe rounds off the collection with an insider's view of not-for-profit regulation. Pascoe served as the inaugural Commissioner of the Australian Charities and Not-for-Profits Commission (ACNC) from 2012 to 2017. Her chapter traverses much ground, providing an account of the policy processes that led to the establishment of the regulator, as well as the political turmoil that surrounded it for around three years from 2013. Pascoe also discusses the activities and focus of the ACNC in light of its statutory objects; these include its registration function and its monitoring and compliance functions, but also its efforts to educate and support charities in Australia. In relation to the latter function, Pascoe emphasizes the regulatory culture of the ACNC, with its focus on supporting and guiding a flourishing charity sector. Her chapter concludes with a brief introduction to the ACNC's future priorities, including the harmonization of the legal definition of charity, and the laws relating to charity fundraising, across the whole Australian federation. Overall, her chapter is an insightful introduction to one of the world's youngest and most successful charity regulators, and a case study in the political, cultural and budgetary factors that affect the success of charity regulators everywhere.

Not-for-profit law has a long and rich history, reflecting the significance of not-forprofit activity to social, economic, political and cultural life for hundreds, indeed thousands, of years. However, as this collection demonstrates, many fundamental questions relating to the legal and regulatory settings within which the not-for-profit sector operates remain poorly understood, and in some cases barely even formulated. If the collection inspires future work seeking to broaden and deepen our understanding of those settings, then it will have served its purpose. 